\title{
Optimization Conditions of Wheat Mesophyll Protoplast Isolation
}

\author{
Xingyue Jia ${ }^{1,2}$, Xiaohui Zhang ${ }^{1,2}$, Jingming $Q u^{1,2}$, Rong Han ${ }^{1,2 *}$ \\ ${ }^{1}$ Higher Education Key Laboratory of Plant Molecular and Environmental Stress Response, Shanxi Normal University, Linfen, China \\ ${ }^{2}$ School of Life Science, Shanxi Normal University, Linfen, China \\ Email: ^1454559173@qq.com
}

How to cite this paper: Jia, X.Y., Zhang, X.H., Qu, J.M. and Han, R. (2016) Optimization Conditions of Wheat Mesophyll Protoplast Isolation. Agricultural Sciences, 7, 850858.

http://dx.doi.org/10.4236/as.2016.712077

Received: November 29, 2016

Accepted: December 20, 2016

Published: December 23, 2016

Copyright $\odot 2016$ by authors and Scientific Research Publishing Inc. This work is licensed under the Creative Commons Attribution International License (CC BY 4.0).

http://creativecommons.org/licenses/by/4.0/ (c) (i) Open Access

\begin{abstract}
The research object of this study is "ML7113" wheat leaf, which is used to isolate protoplast with enzyme hydrolysis method. Three main effectors-the concentration of mannitol, enzymolysis time and centrifugal force, affect the production and vitality of protoplast. While the production and vitality of wheat protoplasts were detected by the hemacytometer and the FDA staining respectively. Results showed that, with the increasing concentrations of mannitol during $0.2 \mathrm{M}-0.4 \mathrm{M}$, protoplast yield increases and when the concentration is $0.4 \mathrm{M}$, the protoplast vitality can be up to $95 \%$; with the extension of enzymolysis time in $2 \mathrm{~h}$ to $8 \mathrm{~h}$, protoplast yield reaches a maximum in $6 \mathrm{~h}$, but its vitality achieves the maximum in $4 \mathrm{~h}$; considering a combination of these two factors impacting on protoplast, we obtain the best time to digest for $4 \mathrm{~h}$; meanwhile, with the increasing of the centrifugal force from $500 \mathrm{rpm}-2000 \mathrm{rpm}$, its comprehensive effect of protoplast vitality and yield is the highest when the centrifugal force is $1000 \mathrm{rpm}$ for $2 \mathrm{~min}$ (replicated three times). So $0.4 \mathrm{M}$ mannitol, $4 \mathrm{~h}$ enzymolysis time and $1000 \mathrm{rpm}$ for $2 \mathrm{~min}$ centrifugal force are the best separation condition.
\end{abstract}

\section{Keywords}

Wheat, Protoplast, Mannitol, Enzymolysis Time, Centrifugal Force

\section{Introduction}

Wheat (Triticum aestivum L., $2 \mathrm{n}=6 \mathrm{x}=42$, AABBDD), an allohexaploid species, is the principal food crop used for humans and livestock globally. Wheat is counted among the "big three" cereal crops and is unrivaled in its range of cultivation owing to its extensive agronomic adaptability, and nutritional profile (including essential amino acids, minerals, vitamins, beneficial phytochemicals and dietary fiber) [1] [2]. Plant breeders 
need to focus on the greatest potential to increase wheat yield. Hence, new technologies must be developed to accelerate breeding through improving genotyping and phenotyping methods and by increasing the available genetic diversity in breeding germplasm [3].

The study of plant protoplast could be traced back to the 1960s that the British botanist Cocking used enzyme degrading cell wall to extract protoplast of apical tomato [4]. From then, protoplast research was at the stage of rapid development. For example, Nagata and Takeble first reported tobacco mesophyll protoplast isolated, cultured and regenerated plants obtained in 1970 [5]. Carlson in 1972 used protoplast fusion technical to obtain the first interspecific hybrids from tobacco, which can partially overcome sexual hybridization incompatibility, obtain somatic hybrids, and find a new way to create and breed varieties [6]. Protoplasts removing the cell wall and including the protoplasm and plasma membrane are the living material of a plant or bacterial cell. Plant protoplast ("naked" cell) provides a unique single cell system to underpin several aspects of modern biotechnology [7]. Due to the absent of cell wall, plant protoplasts have been widely used for genetic transformation, cell fusion and somatic mutation to generate unique and novel plants, which result in the requiring of large quantities of high activity protoplasts [8] [9] [10] [11] [12]. Using enzymatic method to obtain protoplasts is fragile and easy to rupture during the following experimental steps, especially isolation, which makes it difficult to long-term culture and monitor biological processes. Therefore, it is necessary to optimize the conditions of protoplast isolation. In this experiment, we used the young leaves of wheat as material and researched the conditions of protoplasts isolation, such as mannitol concentration, enzymolysis time and centrifugal speed. Finally, we analyzed the effects of these factors on the yield and viability of wheat protoplasts. This paper made a preliminary study on the preparing conditions of wheat protoplasts, which can lay the foundation for genetic programs and breeding of new varieties.

\section{Materials and Methods}

\subsection{Materials}

"ML7113" wheat (Triticum aestivum) were kindly provided by Shanxi Provincial Academy of Agricultural Sciences of Wheat. Full seeds were soaked in tap water at room temperature for $0.5 \mathrm{~h}$, and then disinfected with $3 \%$ sodium hypochlorite for 15 25 min, washed 4 - 5 times with sterile water, and planted on petri dish with wet gauze. The seeds were cultured at $24^{\circ} \mathrm{C} \pm 2^{\circ} \mathrm{C}$, under lighting of $100 \mathrm{umol} \mathrm{m}^{-2} \mathrm{~s}^{-1}$ with a cycle of $16 \mathrm{~h} / 8 \mathrm{~h}$ (light/darkness) for $7 \mathrm{~d}$.

\subsection{Isolation of Protoplasts}

Protoplast isolation was performed through the methods described by Guan et al. [13] with special modifications. The enzyme solution includes $20 \mathrm{mM}$ MES pH5.7, 1.0\% (w/v) cellulase R-10 (Yakult Honsha, Tokyo, Japan), 0.25\% (w/v) macerozyme R-10 (Yakult Honsha, Tokyo, Japan) and a certain concentration mannitol. The different mannitol concentrations $(0.2,0.4,0.6$ and $0.8 \mathrm{M}$, with $0.2 \mathrm{M}$ as control, replicated three 
time) were set up for comparison which was used to confirm the best conditions for maximum yield protoplasts. The enzyme solution was placed in a water bath at $28^{\circ} \mathrm{C}$ for $10 \mathrm{~min}$. Then, the bovine serum protein (0.1\%BSA), $10 \mathrm{mM} \mathrm{CaCl}_{2}, 5 \mathrm{mM}$ $\beta$-mercapto-ethanol were added.

The middle region ( $0.5 \mathrm{~cm}$ away from the leaf tip) of young seedlings (Figure 1) was cut into $0.5 \mathrm{~mm}^{2}$ pieces using a new razor blade. After the leaf pieces were place in 0.25 $\mathrm{M}$ mannitol for $3 \mathrm{~min}$, they were transferred to the enzyme solution $(0.3 \mathrm{~g}-0.4 \mathrm{~g} / 5 \mathrm{ml})$ rapidly and were incubated in enzyme solution at $25^{\circ} \mathrm{C} \pm 1^{\circ} \mathrm{C}$ in darkness. To optimize the enzymolysis time, the tissues were digested for $2,4,6$, and $8 \mathrm{~h}$ (with $2 \mathrm{~h}$ as control, replicated three times respectively). After digestion, the enzymolysate was diluted with an equal volume of W5 solution (2 $\mathrm{mM}$ MES, $154 \mathrm{mM} \mathrm{NaCl}, 125 \mathrm{mM} \mathrm{CaCl}_{2}, 5 \mathrm{mM}$ $\mathrm{KCl}, \mathrm{pH}$ 5.7). Then, protoplasts were filtered through nylon membrane (280 mesh). During the purification, the centrifugal force we set up at 500, 1000, 1500 and 2000 $\mathrm{rpm} / \mathrm{min}$ for $2 \mathrm{~min}$ (replicated three times), and the supernatant was discarded. The precipitation at the bottom of the centrifuge tube were the protoplasts, which were washed three times in washing solution (WS) containing $2 \mathrm{mM}$ MES buffer ( $\mathrm{pH}$ 5.7), $125 \mathrm{mM} \mathrm{CaCl}_{2}$ and $154 \mathrm{mM} \mathrm{NaCl}$.

\subsection{Detection of the Yield of Obtained Protoplasts}

The collected protoplasts were diluted appropriately and estimated under light microscope with a hemacytometer for protoplasts yield statistics. The cell count was performed at least three times for each sample. Protoplasts yield was calculated as follows: protoplast yield (protoplasts/g FW) = number of the protoplasts yielded in enzymolysis/fresh weight of the material used in enzymolysis ( $\mathrm{g} \mathrm{FW}$ ).

\subsection{Protoplasts Viability Assessment}

FDA (Sigma, USA) was added in W5 solution containing protoplasts and its final concentration was $0.01 \%$. After incubationed for $10 \mathrm{~min}$ at room temperature, the protoplasts were collected and washed three times in W5 solution. Then, the viability of protoplasts was assessed by Fluorescence microscopy under ultraviolet light. Protoplasts viability was calculated as follows: protoplast viability $(\%)=$ (fluorescent protoplast
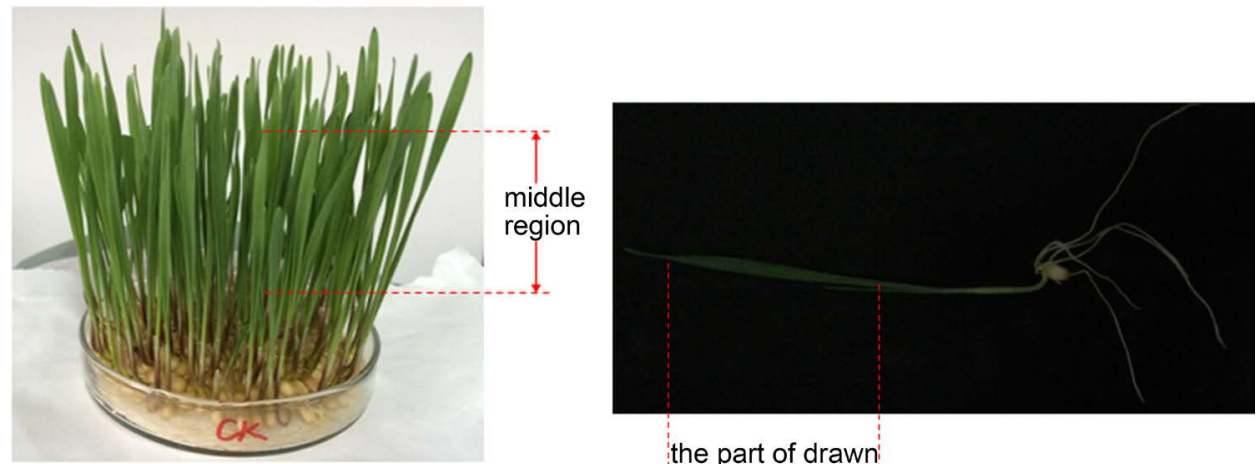

the part of drawn

Figure 1. The used region of the wheat seedings leaves. 
number in view/protoplast total number in view) $\times 100 \%$.

\subsection{Statistical Analysis}

Experimental data were statistically analyzed using analysis of Variance (ANOVA) in SPSS software Version 17.0. Treatment means were separated by least significant difference (LSD) tests at $\mathrm{P} \leq 0.05$.

\section{Results}

\subsection{The Effects of Mannitol Concentration in Enzyme Solution on Protoplasts}

In the process of protoplast isolation, the yield of free protoplast was significantly different under the conditions of adding different mannitol concentration $0.2,0.4,0.6$ and $0.8 \mathrm{M}$. When the mannitol concentration was $0.2-0.4 \mathrm{M}$, with the concentration increased the yield of protoplast was significantly increased and the highest yield of protoplasts was obtained at $0.4 \mathrm{M}(\mathrm{P} \leq 0.05)$, which could reach, at the same time, the vitality could reach $95 \%$ (Figure 2 ). The yields of the protoplasts increased significantly and the highest yield was $7.31 \times 10^{6}$ protoplasts/g FW which appeared at the concentration of the mannitol was $0.4 \mathrm{M}$. While the vitality of the protoplasts showed the same tendency (Figure 2). Then, if continuing to increase the concentration, the yield and activity of protoplast decreased, when mannitol concentration was $0.8 \mathrm{M}$, the yield and activity of protoplast reached the lowest, and the enzyme solution contained more fragments. We analyze the reason for this phenomenon, which may be caused by too high osmotic pressure, causing the protoplast to condense and die. This result indicated that the optimal concentration of mannitol for enzymolysis was $0.4 \mathrm{M}$.

\subsection{The Effects of Enzymolysis Time on Protoplast Isolation}

The effects of enzymolysis time on protoplast yield and viability was determined at 2, 4, 6 and 8 h, respectively, shown as in Figure 3. When the enzymolysis time was $2 \mathrm{~h}$, only

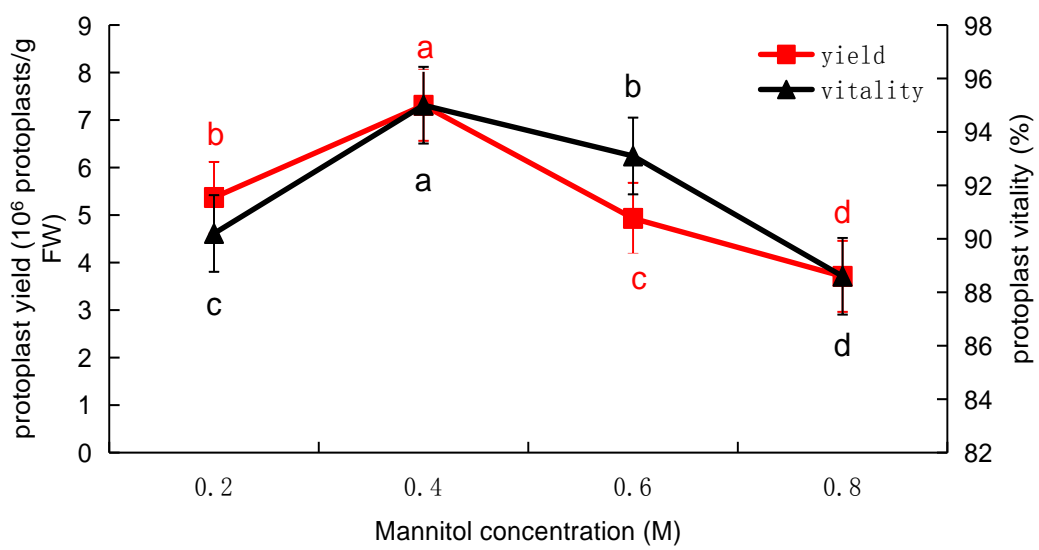

Figure 2. The effects of mannitol concentration on wheat protoplasts yield and viability. Values represent means $\pm S D(n=3)$. The different letters indicate significant differences $(P \leq 0.05)$ according to the LSD test. FW: fresh weight. 


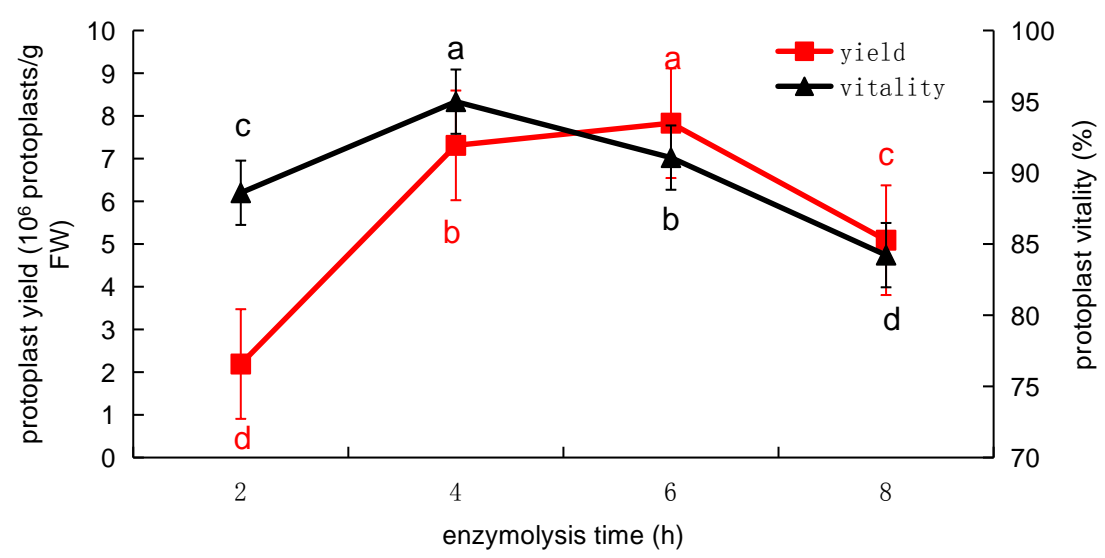

Figure 3. The effects of enzymolysis time on protoplast yield and protoplast viability from wheat. Values represent mean \pm SD $(n=3)$. The different letters indicate significant differences $(\mathrm{P} \leq$ $0.05)$ according to the LSD test.

a small amounts of protoplasts were released. Along with the prolonging of enzymolysis time, the protoplast yields gradually increased. In $4 \mathrm{~h}$, protoplast yield increased greatly, and protoplast viability reached $95 \%$. When enzymolysis time was $6 \mathrm{~h}$, the protoplast yield was the highest, reaching $7.53 \times 10^{6}$ protoplasts/g FW, but the protoplast viability decreased, and the fragments of enzyme solution began to accumulate. When enzymolysis time was $8 \mathrm{~h}$, the yield and viability of protoplasts decreased greatly, the fragments of the enzyme solution was significantly increased, we infer a large number of protoplasts had been broken. Overall, wheat mesophyll protoplast yield and viability were highest when the enzymolysis time was $4 \mathrm{~h}$.

\subsection{The Effects of Different Centrifugal Speed on Yield and Viability of Isolated Protoplast from Wheat}

Under the optimum condition of enzymatic hydrolysis, the solution was centrifuged in a round-bottomed tube for $2 \mathrm{~min}$ at $500 \mathrm{rpm}$ to collect the protoplasts. These protoplasts was observed with the microscope, the yield of protoplast reached $3.37 \times 10^{6}$ protoplasts/g FW, at the same condition, the vitality reached $82.41 \%$ (Figure 4 ), and only a small amount of protoplast and with some impurities was observed. With the increase of centrifugal force, the yield of protoplast also increased. When the centrifugal speed was $1000 \mathrm{rpm}$, the protoplast vitality was the highest, reaching over $95 \%$, and the yield was also higher, reaching $7.31 \times 10^{6}$ protoplasts/g FW. When the centrifugal speed was $1500 \mathrm{rpm}$, the yield of protoplast was the highest, but protoplast viability decreased compared with $1000 \mathrm{rpm}$. Additionally, some debris was found in preparative protoplasts. Compared with $1000 \mathrm{rpm}$ and $1500 \mathrm{rpm}$, under the condition of $2000 \mathrm{rpm}$, both the yield and the vitality of protoplast were the lowest, and the debris increased in solution. In summary, considering protoplast yield, protoplast viability, and impurities, the best centrifugal speed was $1000 \mathrm{rpm}$.

As shown in Figure 5, the protoplasts with a large, round shape were observed under the microscope under the best condition we screened, viable protoplasts exhibited green 


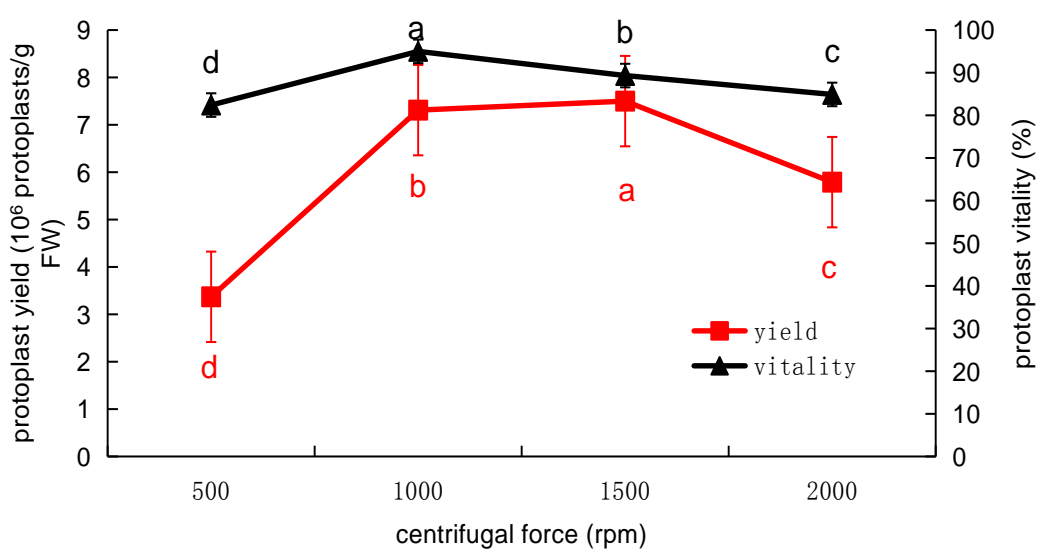

Figure 4. The effects of centrifugal force on protoplast yield and protoplast viability from wheat. Values represent mean $\pm S D(n=3)$. The different letters indicate significant differences $(P \leq$ $0.05)$ according to the LSD test.
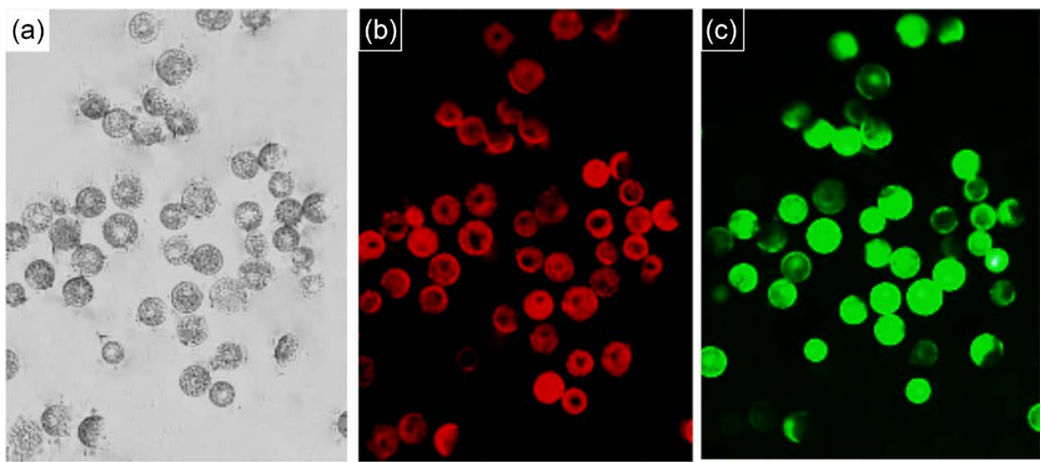

Figure 5. The isolated wheat protoplasts. (a) Bright field images of wheat protoplasts; (b) Autofl uorescence of chloroplasts; (c) Green fluorescence of viable protoplasts after FDA staining (Scale bar $=50 \mu \mathrm{m}$, with $40 \times$ objective) The protoplasts were isolated from the young leaves of wheat when mannitol concentration was $0.4 \mathrm{M}$, enzymolysis time was $4 \mathrm{~h}$ and centrifugal force was 1000 rpm.

fluorescence, accompanied with red autofluorescence of chloroplasts under the fluorescence microscope. The microscopic pictures of protoplasts are shown in Figure 5.

\section{Discussion}

It has been now over 50 years since Cocking (1960) published the first paper describing a method for the isolation of plant protoplasts [14]. Protoplasts that are fragile in osmotic due to without cell walls offer a versatile cell-based experimental system. In general, to establish an efficient expression system requires high-quality protoplasts. Many studies of isolation protoplast have performed in model plants, fewer studies have been carried out in wheat protoplast [15]. In order to obtain high yield and quality protoplasts, we study the several influencing factors, such as enzymatic hydrolysis time, mannitol concentration and centrifugal force. Finally, the average yield of the protoplast reached $5.47 \times 10^{6}$ and the protoplast vitality up to $89.05 \%$.

Protoplasts can be separated from the plant leaves, sheath, stem and other organs. 
However leaves are commonly used as protoplast separation materials because of its wide sources and the loose arrangement of mesophyll cell [16]. Form existing literature, we know that the culture time of wheat have effect on the yield of protoplast. If the cultured time is less than 5 days, the materials are too young to control the enzymolysis time and accompanying with producing lots of separated fragmentations which can cause some troublesome to the late genetic transformation. Even if the concentration of enzyme solution is regulated, the effect is not obvious. If the cultured time is more than 7 days, the enzymolysis time should be increased, while, with the prolong of enzymolysis time, the time is different due to the inconsistent with the leaf maturity, which can cause the early isolated protoplasts broken and produce the fragmentation that have disadvantageous to the later experiments. Finally, we know the optimum incubation time is 5 - 7 days, and the best time is for 7 days. Therefore, to obtain the highest yield and the best quality of the protoplasts in this study, we choose to use leaf of 7 days wheat seedlings as materials.

Enzymatic hydrolysis is the main method to isolate plant protoplasts, and the factors such as the enzyme concentration, osmotic pressure and enzymolysis time have significant effects on the yield and viability of protoplast. With the different of materials, the enzyme concentration is also different [17] [18]. Beyond that, previous study found that mannitol has a influence on the penetration environment of protoplast, and too high or too low osmotic pressure can cause cell membrane rupture, cell disintegration, therefore, this study chooses the mannitol as enzyme liquid osmotic pressure regulator [19]. The experiment that enzyme solutions with different concentrations of mannitol prepare protoplast found the cells can keep stable form, the rule of spherical, be not expansion and shrinkage, have rarely broken cells, and the vigor of protoplast is high when mannitol concentration is $0.4 \mathrm{M}$; under the condition of low and high mannitol concentration, cell expansion and shrinkage leading to broken and producing debris make the yield drop sharply, and cell vitality decrease. Therefore, the effect of mannitol concentration on protoplast isolation efficiency is mainly due to its effect on cell stability, but not on its effect on enzyme activity. This experiment obtain that the appropriate osmotic pressure environment of wheat mesophyll protoplast is $0.4 \mathrm{M}$.

The enzymolysis time is another important factor affecting the protoplast isolation. If the time is too long, enzyme liquid damage plasma membrane of releasing protoplast and reduce the stability of the protoplast, which will reduce its energy even burst; too short enzymatic hydrolysis cannot achieve good separation effect [20]. As the enzymatic hydrolysis time extended, the release of plasma has been rupture, therefore, protoplast yield began to drop after enzymolysis $6 \mathrm{~h}$; also, protoplast vitality reach the highest when enzymolysis time is $4 \mathrm{~h}$, along with the enzymolysis to continue, the amount of cellular debris will be more and more, and vitality began to decline. Apparently, the optimum enzymolysis time is $4 \mathrm{~h}$. According to Sun He et al. wheat leaves in 10 days was used as material to isolate protoplasts, and the best ratio of cellulose and macerozyme in the enzymatic liquid is $1.5 \%$ and $0.5 \%$ respectively, as well as, the yield of protoplast can reach $6 \times 10^{6} / \mathrm{g} \mathrm{FW}$ after enzymatic $5 \mathrm{~h}$ [21]. In this study, using the enzymatic liq- 
uid containing $1.0 \%$ cellulose and $0.25 \%$ macerozyme to isolate protoplast from the leaf of 7-day-old wheat seeding, we find the yield of protoplast can be up to $7.31 \times 10^{6} / \mathrm{g} \mathrm{FW}$ after enzymatic $4 \mathrm{~h}$, which not only shorten the enzymolysis time, but also increase the yield of protoplasts.

Besides, we find that the larger or smaller centrifugal force are influential to the yield of protoplast, more protoplasts are still floating in supernatant fluid when centrifugal speed is $500 \mathrm{rpm}$, which shows that more protoplasts yield increase at first and then decrease, the yield of protoplast reach the highest under $1500 \mathrm{rpm}$, but in enzyme liquid, its fragments obviously increase, which may be due to the greater centrifugal force is, the heavier the protoplast of mechanical damage is, eventually leading to the decrease of the protoplast yield at $2000 \mathrm{rpm}$. Protoplast, however, as a basis of the experimental material, the high vigor protoplast for the subsequent training and other operation is more important on the premise of meeting the quantity demand. To comprehensively consider the effect of centrifugal force on yield and vitality the best centrifugal force of wheat protoplast separation is $1000 \mathrm{rpm}$.

This text only preliminarily study the main factors affecting the protoplast separation, but there are many factors to be considered in protoplast digestion process, such as the $\mathrm{pH}$ of enzymolysis liquid, the purity of enzyme, enzymolysis temperature, plant growth condition. So more detail experiments should be done to further improve the quantity of the protoplast separation.

\section{Conclusion}

Comprehensive protoplast yields viability and other considerations, to determine the optimum conditions for 7-day-old wheat mesophyll protoplast separation as follows: enzyme solution combination of $1.0 \%$ cellulase and $0.25 \%$ macerozyme, mannitol concentration was $0.4 \mathrm{M}$; enzymolysis time was $4 \mathrm{~h}$ and the centrifugal force was $1000 \mathrm{rpm}$; protoplast yields up to $7.31 \times 10^{6} / \mathrm{g} \cdot \mathrm{FW}$ and isolated protoplasts were full of sphericity; the viability was more than $95 \%$.

\section{References}

[1] Shewry, P.R. (2009) Wheat. Journal of Experimental Botany, 60, 1537-1553. https://doi.org/10.1093/jxb/erp058

[2] Yu, Y., Guo, G., Lv, D., et al. (2013) Transcriptome Analysis during Seed Germination of Elite Chinese Bread Wheat Cultivar Jimai 20. BMC Plant Biology, 14, 1-19.

[3] Mark, T. and Peter, L. (2010) Breeding Technologies to Increase Crop Production in a Changing World. Science, 327, 818-822. https://doi.org/10.1126/science.1183700

[4] Cocking, E.C. (1960) A Method for the Isolation of Plant Protoplasts and Vacuoles. Nature, 187, 962-963. https://doi.org/10.1038/187962a0

[5] Nagata, T. and Takebe, I. (1970) Cell Wall Regeneration and Cell Division in Isolated Tobacco Mesophyll Protoplasts. Planta, 92, 301-308. https://doi.org/10.1007/BF00385097

[6] Liu, J.H. and Deng, X.X. (1999) Plant Protoplast Asymmetric Fusion and Its Application in Breeding. Life Sciences, A01, 88-91.

[7] Davey, M.R., Anthony, P., Power, J.B., et al. (2005) Plant Protoplasts: Status and Biotech- 
nological Perspectives. Biotechnology Advances, 23, 131-171.

https://doi.org/10.1016/j.biotechadv.2004.09.008

[8] Kiełkowska, A. and Adamus, A. (2012) An Alginate-Layer Technique for Culture of Brassica oleracea L. Protoplasts. In Vitro Cellular \& Developmental Biology_Plant, 48, 265-273. https://doi.org/10.1007/s11627-012-9431-6

[9] Karamian, R. and Ranjbar, M. (2010) Somatic Embryogenesis and Plantlet Regeneration from Protoplast Culture of Muscari neglectum Guss. African Journal of Biotechnology, 10, 4602-4607.

[10] Sinha, A. and Caligari, P.D.S. (2005) Enhanced Protoplast Division by Encapsulation in Droplets: An Advance towards Somatic Hybridisation in Recalcitrant White Lupin. American Psychologist, 146, 441-448. https://doi.org/10.1111/j.1744-7348.2005.040097.x

[11] Korlach, J. and Zoglauer, K. (1995) Developmental Patterns during Direct Somatic Embryogenesis in Protoplast Cultures of European Larch (Larix decidua Mill.). Plant Cell Reports, 15, 242-247. https://doi.org/10.1007/BF00193728

[12] Aoyagi, H. (2011) Application of Plant Protoplasts for the Production of Useful Metabolites. Biochemical Engineering Journal, 56, 1-8. https://doi.org/10.1016/j.bej.2010.05.004

[13] Guan, Q.Z., Guo, Y.H., Wei, Y.X., Meng, F. and Zhang, Z. (2010) Regeneration of Somatic Hybrids of Ginger via Chemical Protoplast Fusion. Plant Cell Tissue \& Organ Culture, 102, 279-284. https://doi.org/10.1007/s11240-010-9730-8

[14] Huang, H., Wang, Z., Cheng, J., et al. (2013) An Efficient Cucumber (Cucumis sativus, L.) Protoplast Isolation and Transient Expression System. Scientia Horticulturae, 150, 206-212. https://doi.org/10.1016/j.scienta.2012.11.011

[15] Chen, H. and Han, R. (2016) Characterization of Actin Filament Dynamics during Mitosis in Wheat Protoplasts under UV-B Radiation. Scientific Reports, 6, Article Number: 20115. https://doi.org/10.1038/srep20115

[16] Peng, X.Q., Tang, R. and Xie, X.M. (2015) Advances on the Isolation of Protoplast in Gramineous Plant. Chinese Agricultural Science Bulletin, 31, 252-257.

[17] Cao, J., Yao, D., Lin, F. and Jiang, M. (2014) PEG-Mediated Transient Gent Expression and Silencing System in Maize Mesophyll Protoplasts: A Valuable Tool for Signal Transduction Study in Maize. Acta Physiologiae Plantarum, 36, 1271-1281. https://doi.org/10.1007/s11738-014-1508-x

[18] Yang, J.W., Fu, J.X., Li, J., et al. (2014) A Novel Co-Immunoprecipitation Protocol Based on Protoplast Transient Gene Expression for Studying Protein-Protein Interactions in Rice. Plant Molecular Biology Reporter, 32, 153-161. https://doi.org/10.1007/s11105-013-0633-9

[19] Ma, F. and Li, J. (1999) Protoplast Culture and Plant Regeneration of Chinese Plum. Acta Universitatis Agriculturalis Boreali-Occidentalis, 27, 61-65.

[20] Firoozabady, E. (1986) Rapid Plant Regeneration from Nicotiana, Mesophyll Protoplasts. Plant Science, 46, 127-131. https://doi.org/10.1016/0168-9452(86)90119-6

[21] He, S., Lang, Z. and Li, Z. (2013) Optimized Condition for Protoplast Isolation from Maize, Wheat and Rice Leaves. Chinese Journal of Biotechnology, 29, 224-234. 
Submit or recommend next manuscript to SCIRP and we will provide best service for you:

Accepting pre-submission inquiries through Email, Facebook, LinkedIn, Twitter, etc. A wide selection of journals (inclusive of 9 subjects, more than 200 journals)

Providing 24-hour high-quality service

User-friendly online submission system

Fair and swift peer-review system

Efficient typesetting and proofreading procedure

Display of the result of downloads and visits, as well as the number of cited articles

Maximum dissemination of your research work

Submit your manuscript at: http://papersubmission.scirp.org/

Or contact as@scirp.org 